\title{
A large outbreak of bovine botulism possibly linked to a massive contamination of grass silage by type D/C Clostridium botulinum spores on a farm with dairy and poultry operations
}

\author{
A. RELUN ${ }^{1,2}$, L. DORSO ${ }^{1,3}$, A. DOUART ${ }^{1}$, C. CHARTIER $^{1,2}$, R. GUATTEO $^{1,2}$, \\ C. MAZUET ${ }^{4}$, M. R. POPOFF ${ }^{4}$ AND S. ASSIÉ ${ }^{1,2,3}$ \\ ${ }^{1}$ Clinic for Ruminants, Oniris, La Chantrerie, 44307, Nantes, France \\ ${ }^{2}$ BIOEPAR, INRA, Oniris, La Chantrerie, 44307, Nantes, France \\ ${ }^{3}$ Pathology Service for Large Animals, University Animal Hospital, Oniris, La Chantrerie, 44307, Nantes, \\ France \\ ${ }^{4}$ National Reference Center for Anaerobic Bacteria and Botulism, Pasteur Institute, 75724, Paris, France
}

Received 15 May 2017; Final revision 18 September 2017; Accepted 25 September 2016; first published online 2 November 2017

\section{SUMMARY}

Type D bovine botulism outbreaks associated with poultry litter are increasingly reported in European countries, but the circumstances of exposure to Clostridium botulinum toxins remain unclear. In spring 2015, a large type D/C bovine botulism outbreak affected a farm with dairy and poultry operations. Epidemiological and laboratory investigations strongly suggest that the outbreak was caused by feeding cattle with insufficiently acidified grass silage that was contaminated by type D/C C. botulinum spores. The source of the spores remains unclear, but could have been a stack of poultry litter stored in the grass silage pasture before harvesting. The presence of putrefied poultry carcasses mixed in with the litter is relatively unlikely considering the careful daily removal of poultry carcasses. These findings reinforce the importance of proper ensiling of feed materials and highlight the need for safe disposal of poultry litter, even in the case of good management of poultry deadstock, in order to prevent bovine botulism.

Key words: Botulism, cattle, infectious disease epidemiology, poultry litter, silage.

\section{INTRODUCTION}

Botulism is a severe neuroparalytic disease that affects humans, all warm-blooded animals and some fishes. The disease is caused by exposure to botulinum neurotoxins (BoNTs) produced by anaerobic, spore-forming, ubiquitous bacteria of the genus Clostridium, referred to as BoNT-producing clostridia

\footnotetext{
* Author for correspondence: Anne Relun, Oniris, Atlanpole La Chantrerie, 102 Route de Gachet/CS 40706, 44307 Nantes Cedex 3, France.

(Email: anne.relun@oniris-nantes.fr)
}

[1]. BoNTs interfere with acetylcholine release at the neuromuscular junction, which causes a progressive, symmetrical, flaccid muscle paralysis that leads to recumbency and death. Whereas human botulism is quite rare and well managed nowadays; botulism in animals represents a serious welfare and economic concern because of limited options for treatment and the subsequent high mortality rate [2, 3]. Knowledge about potential mechanisms of transmission is therefore crucial to effectively prevent outbreaks.

BoNT-producing clostridia comprise six phylogenetically distinct clostridial groups: Clostridium botulinum groups I, II, III; Clostridium argentinense; 
some strains of Clostridium butyricum and Clostridium baratii $[1,4]$. These bacteria can survive for many years in the form of highly resistant spores in soil and aquatic sediments, as well as in the gastrointestinal (GI) tracts of livestock animals, wild birds and fishes [5-7]. When the conditions are suitable, the spores develop into vegetative forms and may produce one of the seven serotypically distinct BoNTs, denoted A to G. Suitable growth conditions can be defined in general as anaerobic conditions with a protein source, sufficient temperature and moisture, low salinity and low acidity. For animals, these conditions can be found in decaying carcasses, insufficiently acidified silage or decomposing vegetation in ponds [6]. In addition, in types $\mathrm{C}$ and $\mathrm{D}$, some strains are a mosaic $\mathrm{D} / \mathrm{C}$ or $\mathrm{C} / \mathrm{D}$ form, which possesses gene coding for two-thirds of the type $\mathrm{D}$ (or C) toxin and gene coding for one-third of the type C (or D) [8].

Susceptibility to BoNTs seems to be highly variable among the different animal species. Human botulism cases are mainly due to serotypes A, B, E and F - produced by group I and II organisms, C. butyricum and C. baratii - whereas reported animal cases are mostly associated with serotypes $\mathrm{C}$ and $\mathrm{D}$ produced by group III organisms.

The route of contamination in cattle is assumed to be primarily the ingestion of preformed toxins in food, water or carrion [6, 9]. The first outbreaks reported were mainly attributed to bones licked by cattle grazing in phosphorous-deficient areas [10, 11], ingestion of water or silage contaminated by small mammal or bird carcasses $[12,13]$, use of poultry litter as a dietary supplement $[14,15]$, ingestion of insufficiently acidified silage contaminated by telluric $C$. botulinum spores [16, 17], or feeding silage made from contaminated brewers' grains [18]. In the past few decades, an increasing number of cattle botulism type D outbreaks linked to direct contact with or close proximity to poultry litter has been reported in Western Europe [19-21]. Most of these outbreaks have been attributed to the ingestion of BoNTs from poultry or small mammal carcasses that were present in poultry litter spread as fertilizer or stacked onto pastures, but the causal association has not always been proved [21-23].

In spring 2015, a large outbreak of type $\mathrm{D} / \mathrm{C}$ bovine botulism occurred on a farm with dairy and poultry operations in Western France. The objective of this study was to investigate the mode of exposure of cattle, with particular emphasis on the potential role of poultry litter and carcasses.

\section{METHODS}

\section{Outbreak description}

An outbreak of botulism occurred in spring 2015 on a farm with dairy and poultry operations in Western France. Dairy cattle, broilers and laying hens were reared at four different sites approximately $600 \mathrm{~m}$ apart. Milking cows were reared at site 1, grazed in summer and housed in a cubicle house during the winter period. The herd was divided into two feeding groups according to the level of production (LP: lowproducing cows, HP: high-producing cows), and fed a mixed ration based on maize and grass silage. Each group was conducted separately with different feeding regimen and different access to pastures, in terms of date of access and patch of pasture grazed.

From 20 March (day 1 of the outbreak) to 11 May (day 57), 80 of 110 Holstein cows died after having developed signs of muscle weakness that began in the hind limbs and gradually led to sternal and then lateral recumbency. At least three cows also had dysphagia, with difficulty swallowing and excessive salivation. No flaccid tongue was observed. Clinical signs progressed rapidly and death occurred on average within $48 \mathrm{~h}$ (ranging from $3 \mathrm{~h}$ to 8 days), despite supportive treatments.

Vaccination against $C$. botulinum was initiated on day 51 , with a second injection on day 85 , using a bivalent $\mathrm{C}$ and $\mathrm{D}$ botulinum toxoid (Ultravac ${ }^{\circledR}$ Botulinum, Zoetis France) available in France under emergency drug release. All cows introduced after that date were vaccinated with a primary series on arrival. Two additional cows died on days 75 and 88 after showing the same clinical signs.

No calves, heifers or bulls exhibited any clinical signs, nor did the two flocks of poultry broilers or the flock of laying hens.

\section{Necropsy and sampling of animal biological material}

Two carcasses were sent on day 7 to the regional veterinary laboratory and two others on day 40 to the University Veterinary Hospital (Oniris, Nantes, France) for necropsy and laboratory investigations.

Routine necropsic examination was performed and samples of intestinal content were sent to the Pasteur Institute (Paris, France) for $C$. botulinum examination. The serum of 10 other affected cows was sent to the Pasteur Institute for $C$. botulinum examination on day 40. Samples of intestinal content of one cow were sent to the Departmental Veterinary Diagnostic 
Laboratory (Inovalys, Nantes, France), for C. perfringens examination on day 40 .

\section{Epidemiological investigation}

The local veterinary practitioner requested assistance from the Veterinary University to identify the source of contamination. The farm was visited by the first author and the local veterinarian 94 days after the onset of the outbreak. We examined the distribution of events over time and space, silage collection, feed and water distribution, pasture fertilization, as well as the management of poultry carcasses and poultry litter.

\section{Food specimen collection and processing}

The silages used to feed dairy cattle were observed during the farm visit (day 94). Silage suspected to be involved as a medium of $C$. botulinum or its toxin was sampled on day 106 by the veterinary practitioner (50 g of silage, sampled in three anaerobic areas of the silage), and sent in a closed plastic tube at ambient temperature to the Pasteur Institute (Paris, France) for C. botulinum examination.

\section{Laboratory analysis}

$C$. perfringens bacteria and toxins $(\alpha, \beta, \varepsilon)$ were searched by ELISA (Bio X Diagnostics ${ }^{\mathrm{ND}}$, Jemelle, Belgium).

Detection of BoNT in animal and food samples was based on a mouse lethality assay. The tests were performed in accordance with the European Directive 2010/63/EU on the protection of animals used for scientific purposes (laboratory animal use agreement $\mathrm{n}^{\circ}$ 2013-0116). Botulinum toxin from $10 \mathrm{~g}$ of food samples was extracted by incubating the sample 30 min at room temperature in $20 \mathrm{ml}$ of $50 \mathrm{mM}$ phosphate buffer ( $\mathrm{pH} 6.5$ ) containing $1 \%$ gelatin. The extract was then centrifuged end filtered and $0.5 \mathrm{ml}$ was injected intraperitoneally into Swiss mice weighing 20-22 g (Charles River Laboratories, l'Arbresle, France). The mice were observed for up to 4 days for the presence of typical clinical signs (pinching of the waist, laboured breathing and paresis) and euthanized immediately after observation of such signs. BoNTs were confirmed, and types were identified using a seroneutralization test on mice with specific botulinum antitoxins for types $\mathrm{C}$ and $\mathrm{D}$ from the
National Reference Center for Anaerobic Bacteria and Botulism [24, 25].

Detection of $C$. botulinum in food and bovine intestinal contents and blood samples was based on culturing samples in freshly prepared fortified cooked meat medium at $37^{\circ} \mathrm{C}$ under anaerobic conditions [26]. After a $48 \mathrm{~h}$ period of incubation, $1 \mathrm{ml}$ of enrichment culture was collected and DNA extracted from the pellet cells using a QIAamp DNA Stool Kit (Qiagen) according to the manufacturer's instructions. Detection of BoNT genes (bont), namely bontC, bontD, bontC/Dand bontD/C, was performed by SYBR green real-time PCR using the following primers and according to the protocol previously described [Vanhomwegen et al., PLoS ONE. 2013; 8 (6): e67510]

bonT/C: P1652 GGCACAAGAAGGATTTGG TG P1653 TTGGATCCATGCAAAATTCA

bont/D: P1654 TTGGGCGAATGAAGTAGTTG P1655 TCCCCTTAATGCTGAATTTCC

bont/CD: P1795 TGAAAATGCATACACGCCA

GT P1796 TACCCATCCTGGATCCCTAGA

bont/DC: P1797 CCACTAGGTGCATTGGATCA P1798 TCCAAGCCTATTTGTTGTTGC.

The presence and the type of viable and toxic C. botulinum strains in the samples were confirmed by the detection of botulinum toxin in the culture supernatant performed by the mouse lethality and seroprotection assay after 4 days of enrichment cultures.

\section{RESULTS}

\section{Necropsy findings}

No significant gross lesions were found, except for petechiae and suffusions on mucosal and serous surfaces for two cows (day 40), as well as congestion of the abomasal mucosa and segments of the small and large intestines for one cow (day 40). None of the cows were observed with intestinal haemorrhage or decayed carcass material in their stomach contents.

\section{Distribution of events in space and time}

Figure 1 represents the patches of pastures grazed by the cows during the outbreak. Figure 2 represents the evolution in time of deaths, the grass silage fed (A or B) and the patch of pasture grazed.

Before the onset of the outbreak, all milking cows and yearling heifers were reared indoors at sites 1 and 3 , respectively, and fed grass silage $\mathrm{B}$, whereas 


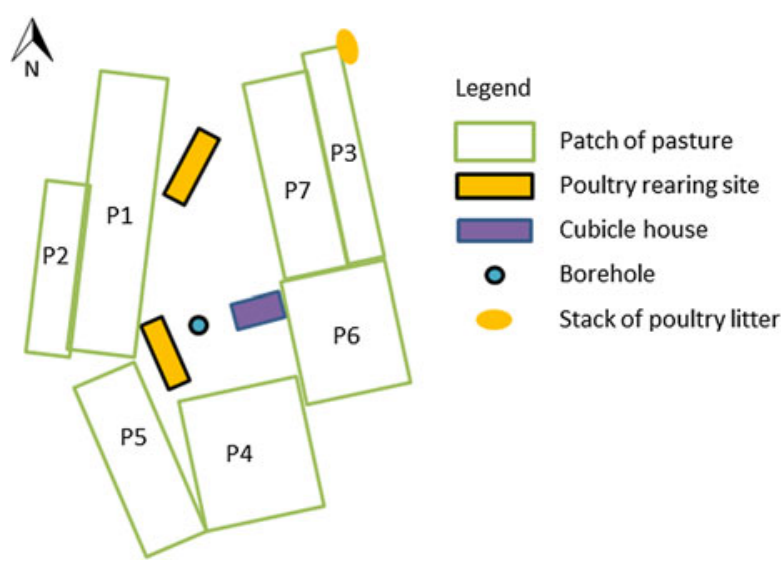

Fig. 1. Layout of the dairy farm site (site 1) that experienced a massive outbreak of type D/C botulism in Western France in spring 2015.

senior heifers grazed at site 2 and were fed grass silage A.

Deaths occurred in two waves. The first lasted from day 1 to day 26 and affected only cows in the LP group (10 deaths). Four cows were placed by the farmer as sentinel animals between days 16 and 29 on a patch of pasture previously grazed by the affected cows, without exhibiting any clinical signs. The second wave lasted from day 31 to day 57 and affected both groups (LP and HP) of cows (70 deaths). The four sentinel cows were moved to a patch of pasture not previously used and fed grass silage A from day 42 to day 45 . One of them died on day 45 .

Except for the two late cases, all deaths occurred within 19 days after the ingestion of grass silage A (Fig. 2). The cow that died on day 75 had not been vaccinated as she should have been culled earlier. The cow that died on day 88 calved on day 49 , had received two injections of the vaccine and had never been fed grass silage $\mathrm{A}$.

Senior heifers were fed with grass silage A until day 39 without exhibiting any clinical signs.

The bulls and calves were not fed any grass silage.

\section{Silage collection, feed and drinking-water distribution}

Grass silage A was prepared from a pasture located 4 $\mathrm{km}$ away. Forage was sown on 10 July 2014, harvested on 15 September 2015 and stored in a $7 \times 6 \mathrm{~m}$ bunker silo with concrete floor at site 2 . The weather prevented the farmer from waiting for normal prewilting. At the end of storage, the silage stack was $1.5 \mathrm{~m}$ high. The first ration containing grass silage A was distributed to the senior heifers at the beginning of winter. When the clinical signs began, 7 days after its distribution to LP group, the silage stack was around $4 \mathrm{~m}$ in length and $1 \mathrm{~m}$ high, or about $28 \mathrm{~m}^{3}$. When it was analysed for botulism, only about $6 \mathrm{~m}^{3}$ remained.

Grass silage B was prepared from a pasture located close to site 2. Forage was sown in August 2013, harvested in May 2014, and stored after pre-wilting in a $9 \times 16 \mathrm{~m}$ bunker silo with concrete floor at site 3 . No additive was used.

Both silages were comprised of ryegrass, clover and hairy vetch. They were covered with a standard black plastic sheet $(150 \mu \mathrm{m}$ thick) and tyres.

Feed was mixed manually for heifers and bulls, but with a mixer for milking cows. A hay bale was distributed weekly to milking cows. The farmer reported that he had observed some refusal of grass silage A by the senior heifers.

All cattle, heifers, bulls and calves drunk water from a water borehole located on site 1 (Fig. 1).

\section{Pasture fertilization}

All patches of pastures at site 1 were fertilized with dairy cattle manure on 15 March 2015, except patches 1 and 2, which had not been fertilized in the previous years. The manure came from the farm. Silage pastures were fertilized with a mineral fertilizer.

\section{Management of poultry carcasses and poultry litter}

Poultry flocks were checked daily for the occurrence of mortality and any carcasses were immediately removed, stored in a freezer and disposed of in a rendering container before rendering plant pick-up.

Poultry litter was stored and stacked alongside pastures. One stack was stored next to grazing pastures at site 1 and separated by an electric fence to prevent access by grazing cattle (Fig. 1). This stack was collected by a contractor every 2 weeks. The prevailing wind direction is west to east, but an east to west wind blew on several occasions before and during the outbreak. Dispersion of litter particles by wind overgrazing pastures cannot be excluded, but contamination of the patch of pasture grazed at the onset of the outbreak (patch 1) is unlikely, as this patch is protected from the easterly wind by the poultry housing (Fig. 1). The stack of poultry litter was stored slightly below the pastures, which should have prevented flowing water from carrying litter particles towards grazing pastures. 

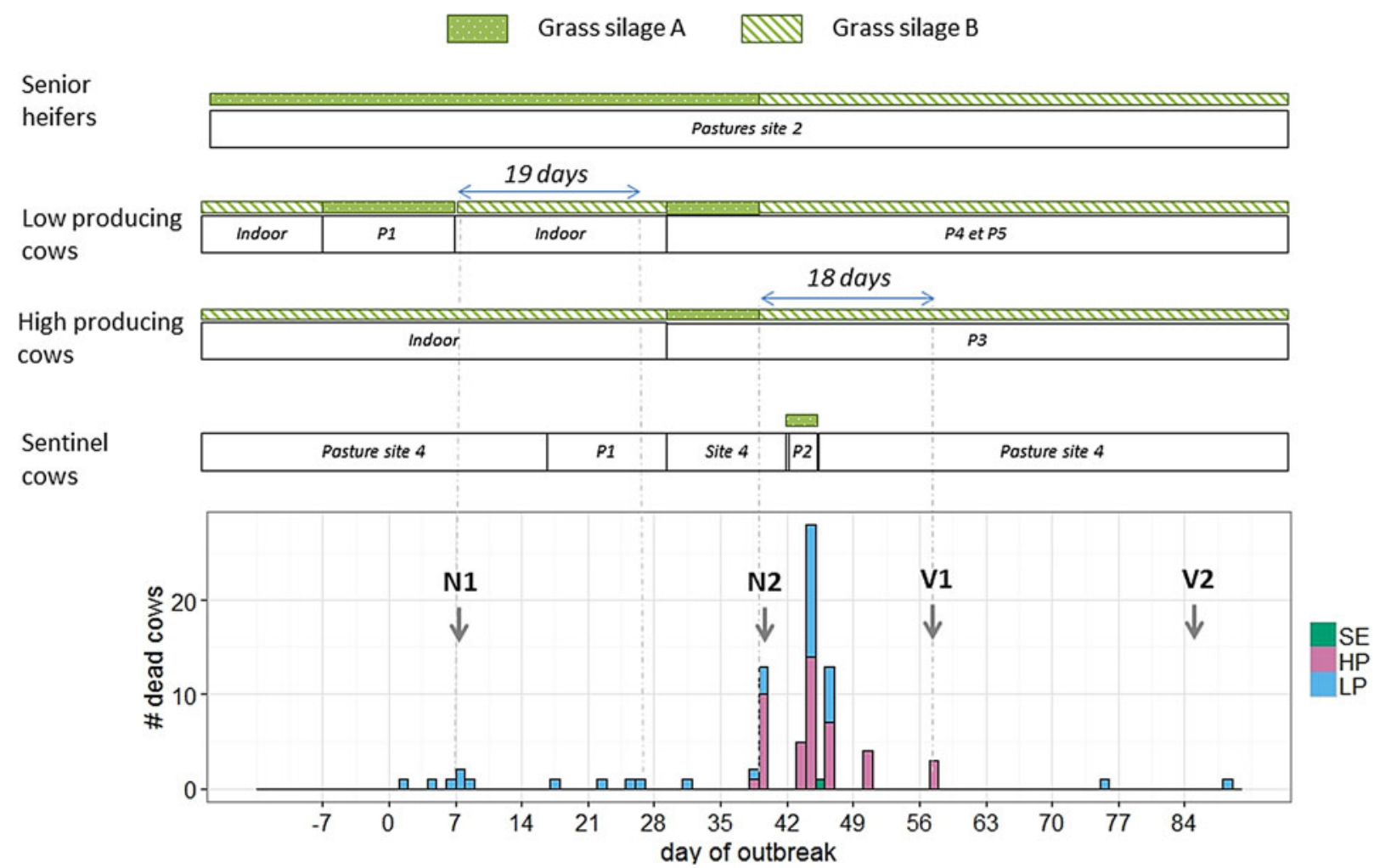

Fig. 2. Distribution of events in time and space during an outbreak of type $\mathrm{D} / \mathrm{C}$ botulism in a Holstein dairy herd in Western France in spring 2015 (P: patch of pasture at site 1; N: necropsy; V: vaccination against Clostridium botulinum; SE: sentinel cows; HP: high-producing cows; LP: low-producing cows).

Two stacks of poultry and dairy cattle litter were stored in the middle of silage pastures to be used as fertilizer on maize crops (pasture located $4 \mathrm{~km}$ away from which grass silage A was prepared). These stacks had been stored for the duration of grass growth and were present during harvesting of grass silage A.

\section{Observation of grass silage}

No carcasses were observed in any silage by the farmer. During the farm visit on day 94, the two grass silages were inspected. Grass silage A was a very dark olive green, moist, with a very offensive odour (a putrid ammonia smell). Grass silage B was straw yellow, with a slightly sweet acidic smell (Fig. 3).

As grass silage A was the most likely medium of C. botulinum or its toxin, it was sampled on day 106 and sent to the Pasteur Institute (Paris, France) for C. botulinum examination.

\section{Laboratory results}

C. botulinum type $\mathrm{D} / \mathrm{C}$ bacteria were detected in a sample of intestinal content from one of the four cows (day 40) by PCR and mouse bioassay after anaerobic enrichment. No BoNT was detected either in the samples of intestinal contents from the four cows or in the serum of 10 other affected cows. C. perfringens was detected in the intestinal content of the cow examined (day 40 ), but not its toxins $(\alpha, \beta, \varepsilon)$.

$C$. botulinum type $\mathrm{D} / \mathrm{C}$ bacteria were detected in grass silage $\mathrm{A}$ by $\mathrm{PCR}$ and mouse bioassay after anaerobic enrichment. No BoNT was detected in the grass silage.

\section{DISCUSSION}

In the past few decades, an increasing number of type D botulism outbreaks have been reported in cattle in Western Europe and were linked to contact with or close proximity to poultry litter. The presence of carcasses of birds that died during production was regarded as the likely source of BoNTs, the cattle being exposed through direct ingestion of litter, ingestion of particles containing BoNTs spread onto pastures by scavengers, or ingestion of grass silage fertilized with poultry litter [19, 21]. This study is the first to suggest that large amounts of grass silage can 

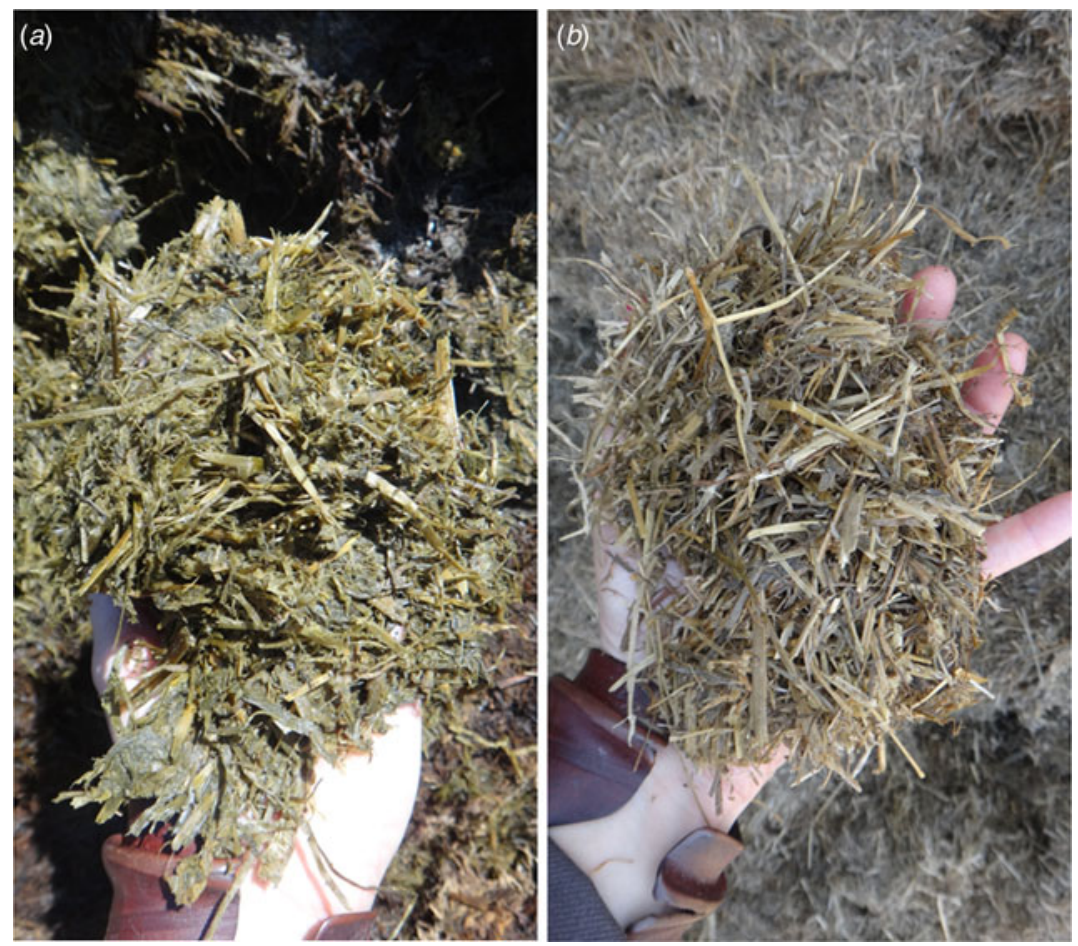

Fig. 3. Observation of two batches of grass silage fed during an outbreak of type $\mathrm{D} / \mathrm{C}$ botulism in a Holstein dairy herd in Western France in spring 2015. The silage A was harvested in September 2015 and the silage B in May 2014.

be contaminated with type $\mathrm{D} / \mathrm{C}$ C. botulinum spores in the absence of pasture fertilization with poultry litter, and that poultry litter may be at risk even with proper management of poultry carcasses.

The definite diagnosis of botulism should rely on the detection of BoNTs by mouse bioassay in serum, ruminal fluid, intestinal contents of tissue of affected animals [24]. However, definite diagnosis is usually difficult in cattle as BoNTs are rapidly degraded by ruminal microbes [27] and in post-mortem tissue [28], and BoNTs concentration in the serum of clinically affected cattle may be below the threshold of detection of the bioassay [16], giving false-negative results. Diagnosis of bovine botulism thus mostly relies on the observation of typical signs and ruling out of other potential causes of the problem [29]. A circumstantial diagnosis can be made by finding the organism and BoNTs in foodstuffs that recently have been consumed by the animals exhibiting clinical signs of botulism or by test feeding of suspect toxic feed to susceptible animals [24, 29].

In this case, the typical clinical signs of botulism were observed in cows in the 18 days following the ingestion of grass silage $\mathrm{A}$; this silage was dark green, moist and had a really unpleasant odour, which is characteristic of clostridial contamination $[30,31]$; the viable type $\mathrm{D} / \mathrm{C} \quad C$. botulinum was detected by PCR and mouse bioassay in the grass silage $\mathrm{A}$ and the intestinal content of one affected cow. Moreover, one of the four sentinel cows showed signs of botulism and died after 3 days of consumption of this grass silage. All of these findings confirm the diagnosis of botulism and strongly suggest the implication of this silage as the medium that allowed growth and toxin production from $C$. botulinum spores $[24,30]$.

While the accidental contamination of the grass silage by soil, animals trapped during harvesting or burrowing animals that died in the stored silage should have spoiled only a pocket of the silage, the detection of type D/C C. botulinum in grass silage at the end of the outbreak, after at least 15 days of distribution and more than $20 \mathrm{~m}^{3}$ distributed, suggests massive contamination of the silage before harvesting. Since no poultry manure had been used as a fertilizer on silage pastures, the most likely mode of silage contamination is the dispersal of particles containing C. botulinum spores by wind or runoff water from a stack of poultry litter that was stored alongside the pasture before silage harvesting. Unfortunately, this stack was not 
present at the time of the epidemiological investigation and could thus not be tested for the presence of C. botulinum spores or toxins.

Two sources have been previously proposed to explain the contamination of poultry litter by $C$. botulinum spores and toxins: the presence of putrefied poultry carcasses mixed in with the litter, or the presence of rodents that were attracted by the litter and died in it $[19,21,22]$. Particles of litter containing the spores or the BoNTs could then be dispersed in the silage pasture by wind, runoff water or scavengers [21, 32]. In the case in question, the presence of putrefied poultry carcasses mixed in with the litter is quite unlikely as the litter came from the farm, which has good management of poultry carcasses, in other words daily inspections and the removal and safe storage of dead birds [21]. The presence of rodent carrion in the litter cannot be excluded, but was not observed by the farmer. Another source can be hypothesized: spores of type D/C C. botulinum could have been present in the litter due to asymptomatic carriage in the poultry gut, as has been observed with type B and C C. botulinum in pigs [33, 34]. Indeed, poultry are less susceptible than cattle to type D botulism [29, 35] and the mosaic D/C form, which possesses gene coding for two-thirds of the type $\mathrm{D}$ toxin and gene coding for one-third of the type $\mathrm{C}$ toxin [8], could be particularly adapted to their carriage by birds $[4,8,36]$. Under this scenario, the occurrence of botulism in cattle would require the growth of spores in adequate substrate, which, in the present outbreak, would be the insufficiently fermented grass silage. Further research on the asymptomatic carriage of type $\mathrm{D} / \mathrm{C} C$. botulinum by poultry would help to better assess the risk of exposure of cattle to $C$. botulinum spores associated with poultry litter. In any event, recommendations for ruminant and poultry farmers on the safe storage and disposal of poultry litter and the proper preparation of silage are still needed to prevent further cattle botulism outbreaks [37].

The grass silage was not initially suspected as a potential vehicle of $C$. botulinum or its toxin, as the senior heifers were not affected, despite being fed this silage, until almost a month after the onset of the outbreak. The difference in botulism development could be due to the differences in feed distribution between milking cows and heifers. The feed was mixed manually for heifers, which could more easily sort and refuse the contaminated silage, as observed by the farmer. Using a mixer may have minimized the poor palatability of clostridial-contaminated silage and made it more difficult to sort the ingredients, thus resulting in the ingestion of the contaminated silage [9]. Another possibility could be that only some of the silage was contaminated and distributed to milking cows, while the rest was uncontaminated or only slightly contaminated and given to the heifers. Finally, the feed mixer could also be contaminated by a spoiled silage pocket or a carcass. However, in this case, we should not have found $C$. botulinum in the silage collected from the bunker silo at the end of the outbreak.

Some authors have hypothesized that cattle exposed to BoNTs were also most likely exposed to spores of C. botulinum, and may thus have developed toxicoinfection caused by C. botulinum colonization of the GI tract and in situ germination and toxin production $[21,32]$. This form of botulism has been reported in human infants and foals, but should not affect adult vertebrates, in which normal intestinal bacteria compete with the germination and growth of BoNTproducing clostridia [2]. A form of toxicoinfection in adult cattle has been described in Germany and called 'visceral botulism'. However, the implication of BoNT-producing clostridia in such a case is still debated [38, 39]. Toxicoinfection has also been suggested to explain longer incubation periods in biphasic botulism outbreaks in cattle [40]. Under this scenario, animals that ingested a smaller amount of BoNTs would be temporarily debilitated, with altered GI tract motility, providing conditions that allow C. botulinum growth and secondary toxicoinfection. In the present outbreak, almost all deaths occurred within 19 days after ingestion of the contaminated grass silage, which is coherent with the incubation period previously described of $24 \mathrm{~h}$ to 17 days $[6,41]$. The death that occurred on day 75, 36 days after the last ingestion of the contaminated silage, could be explained by a secondary toxicoinfection as described by Neill et al. [40]. The last death concerned a cow that had never been fed with the contaminated grass silage. Despite the farmer having reported clinical signs compatible with botulism (weakness of the hind limbs, progressively leading to lateral and sternal recumbency), this case occurred in early lactation and could also be due to other diseases, notably milk fever.

\section{CONCLUSION}

Type D bovine botulism outbreaks linked to contact with or close proximity to poultry litter are 
increasingly reported in Western Europe. Until now, the presence of carcasses of birds that died during production was regarded as the likely source of BoNTs. In this study, the epidemiological and laboratory investigation suggests another contamination scenario, with a stack of poultry litter as the source of C. botulinum spores and insufficiently acidified grass silage as the medium supporting growth and toxin production from C. botulinum spores. As poultry carcasses were collected and removed from the poultry barn daily, it seems unlikely that the source of toxins or spores in poultry litter was poultry carcasses. Asymptomatic carriage of type $\mathrm{D} / \mathrm{C} C$. botulinum organisms by poultry in their gut should be further investigated. These findings highlight the fact that precautions should be taken for the safe disposal of poultry litter and reinforce the importance of proper ensiling of feed materials to prevent bovine botulism.

\section{ACKNOWLEDGEMENTS}

The authors acknowledge the farmers, Dr Maertens (veterinary practitioner, Le Teilleul, France) and Dr Leboeuf (GDS 50, Saint-Lô, France) for their warm welcome and contributions. This research received no specific grant from any funding agency in the commercial or not-for-profit sectors.

\section{DECLARATION OF INTEREST}

None.

\section{ETHICAL STANDARDS}

The authors assert that all procedures contributing to this work comply with the ethical standards of the relevant national and institutional guides on the care and use of laboratory animals.

\section{REFERENCES}

1. Smith TJ, Hill KK, Raphael BH. Historical and current perspectives on Clostridium botulinum diversity. Research in Microbiology 2015; 166: 290-302.

2. Critchley EMR. A comparison of human and animal botulism: a review. Journal of the Royal Society of Medicine 1991; 84: 295-298.

3. Skarin H, et al. The workshop on animal botulism in Europe. Biosecurity and Bioterrorism: Biodefense Strategy, Practice, and Science 2013; 11: S183-S190.

4. Rossetto O, Pirazzini M, Montecucco C. Botulinum neurotoxins: genetic, structural and mechanistic insights. Nature Reviews Microbiology 2014; 12: 535-549.
5. Meyer KF. The status of botulism as a world health problem. Bulletin of the World Health Organization 1956; 15: 281.

6. Deprez P. Tetanus and botulism in animals. In: Mainil J, Duschesnes C, Granum PE, Menozzi MG, et al., eds. Clostridia in Medical, Veterinary and Food Microbiology - Diagnosis and Typing. Brussels: European Commission, 2006, pp. 27-36.

7. Notermans $\mathbf{S}$, Dufrenne $\mathbf{J}$, Oosterom $\mathbf{J}$. Persistence of Clostridium botulinum type B on a cattle farm after an outbreak of botulism. Applied and Environmental Microbiology 1981; 41: 179-183.

8. Moriishi K, et al. Mosaic structures of neurotoxins produced from Clostridium botulinum types $\mathrm{C}$ and D organisms. Biochimica et Biophysica Acta (BBA) - Gene Structure and Expression 1996; 1307: 123-126.

9. Lindström M, et al. Clostridium botulinum in cattle and dairy products. Critical Reviews in Food Science and Nutrition 2010; 50: 281-304.

10. Theiler A, et al. Lamsiekte (parabotulism) in cattle in South Africa: osteophagia and phophorus deficiency in relation to lamsiekt. In: Union of South Africa. Dept. of Agriculture, eds. 11th and 12th Reports of the Director of Veterinary Education and Research. Pretoria: Government Printer and Stationery Office, 1927, pp. 1211-1248.

11. Brizuela CM. Bovine botulism in paraguay. Tropical Animal Health and Production 1996; 28: 221-222.

12. Myllykoski J, et al. Type $C$ bovine botulism outbreak due to carcass contaminated non-acidified silage. Epidemiology \& Infection 2009; 137: 284-293.

13. Doutre MP. Fréquence au Sénégal du botulisme animal d'origine hydrique. Revue d'élevage et de médecine vétérinaire des pays tropicaux 1969; 22: 29-31.

14. Jean D, et al. Clostridium botulinum type C intoxication in feedlot steers being fed ensiled poultry litter. The Canadian Veterinary Journal 1995; 36: 626-628.

15. McLoughlin MF, Mcllroy SG, Neill SD. A major outbreak of botulism in cattle being fed ensiled poultry litter. The Veterinary Record 1988; 122: 579-581.

16. Kelch WJ, et al. Fatal Clostridium botulinum toxicosis in eleven Holstein cattle fed round bale barley haylage. Journal of Veterinary Diagnostic Investigation 2000; 12: 453-455.

17. Divers TJ, et al. Clostridium botulinum type B toxicosis in a herd of cattle and a group of mules. Journal of the American Veterinary Medical Association 1986; 188: 382-386.

18. Notermans S, et al. Incidence of Clostridium botulinum in the rumen contents and faeces of cattle fed brewers' grains naturally contaminated with Clostridium botulinum (author's transl). Tijdschrift voor Diergeneeskunde 1978; 103: 1327-1333.

19. Payne JH, et al. Emergence of suspected type D botulism in ruminants in England and Wales (2001 to 2009), associated with exposure to broiler litter. Veterinary Record 2011; 168: 640.

20. Popoff MR. Revue sur l'épidémiologie du botulisme bovin en France et analyse de sa relation avec les élevages de volailles. Revue Scientifique Technique (International Office of Epizootics) 1989; 8: 129-145. 
21. ACMSF. Ad-hoc group on botulism in cattle. Report on botulism in cattle. The Advisory Committee on the Microbiological Safety of Food. 2006; 2015. (http:// acmsf.food.gov.uk/sites/default/files/mnt/drupal_data/ sources/files/multimedia/pdfs/botulismincattlereport1206. pdf). Accessed 20 April 2017.

22. Smart JL, et al. Poultry waste associated type C botulism in cattle. Epidemiology \& Infection 1987; 98: 73-79.

23. Hogg RA, White VJ, Smith GR. Suspected botulism in cattle associated with poultry litter. Veterinary Record 1990; 126: 476-479.

24. Lindström M, Korkeala H. Laboratory diagnostics of botulism. Clinical Microbiology Reviews 2006; 19: 298-314.

25. Fach $\mathbf{P}$, et al. Investigation of animal botulism outbreaks by PCR and standard methods. FEMS Immunology \& Medical Microbiology 1996; 13: 279-285.

26. Takeda M, et al. Characterization of the neurotoxin produced by isolates associated with avian botulism. Avian Diseases 2005; 49: 376-381.

27. Allison MJ, Maloy SE, Matson RR. Inactivation of Clostridium botulinum toxin by ruminal microbes from cattle and sheep. Applied and Environmental Microbiology 1976; 32: 685-688.

28. Brooks CE, et al. Diagnosis of botulism types C and D in cattle by a monoclonal antibody-based sandwich ELISA. The Veterinary Record 2011; 168: 455.

29. Le Maréchal C, Woudstra C, Fach P. Botulism. In: Uzal FA, Songer JG, Prescott JF, Popoff MR, eds. Clostridial Diseases of Animals. Hoboken, NJ: John Wiley \& Sons, Inc, 2016, pp. 303-330.

30. Jones CM, et al. From Harvest to Feed: Understanding Silage Management. PennState College of Agricultural Sciences, Agricultural Research and Cooperative Exention, 2004 (http://pss.uvm.edu/pdpforage/Materials/ CuttingMgt/From_Harvest_to_Feed_Understanding_ Silage_management_PennState.pdf). Accessed 15 September 2017.
31. Seglar WJ, Shaver RD. Management and assessment of ensiled forages and high-moisture grain. Veterinary Clinics of North America - Food Animal Practice 2014; 30: 507-538.

32. Carlier J-P, Popoff MR. Situation actuelle du botulisme bovin et aviaire en France. Bulletin de l'Académie Vétérinaire de France 2002; 155: 295-302.

33. Myllykoski J, et al. The detection and prevalence of Clostridium botulinum in pig intestinal samples. International Journal of Food Microbiology 2006; 110: 172-177.

34. Yamakawa K, et al. Clostridium botulinum type $\mathrm{C}$ in healthy swine in Japan. Microbiology and Immunology 1992; 36: 29-34.

35. Gross WB, Smith LD. Experimental botulism in gallinaceous birds. Avian Diseases 1971; 15: 716-722.

36. Woudstra C, et al. Neurotoxin gene profiling of Clostridium botulinum types $\mathrm{C}$ and $\mathrm{D}$ native to different countries within Europe. Applied and Environmental Microbiology 2012; 78: 3120-3127.

37. Otter A, et al. Risk of botulism in cattle and sheep arising from contact with broiler litter. Veterinary Record 2006; 159: 186-187.

38. Böhnel H, Schwagerick B, Gessler F. Visceral botulism a new form of bovine Clostridium botulinum toxication. Journal of Veterinary Medicine Series A 2001; 48: 373-383.

39. Seyboldt C, et al. Occurrence of Clostridium botulinum neurotoxin in chronic disease of dairy cows. Veterinary Microbiology 2015; 177: 398-402.

40. Neill SD, McLoughlin MF, McIlroy SG. Type C botulism in cattle being fed ensiled poultry litter. Veterinary Record 1989; 124: 558-560.

41. Anniballi F, et al. Management of animal botulism outbreaks: from clinical suspicion to practical countermeasures to prevent or minimize outbreaks. Biosecurity and Bioterrorism: Biodefense Strategy, Practice, and Science 2013; 11: S191-S199. 